\title{
Some new features of ionospheric plasma depletions over the Indian zone using all sky optical imaging
}

\author{
H. S. S. Sinha and S. Raizada
}

Physical Research Laboratory Navrangpura, Ahmedabad - 380 009, India

(Received February 7, 1999; Revised June 19, 2000; Accepted July 3, 2000)

\begin{abstract}
An all sky optical imaging system was operated from Sriharikota rocket range (SHAR) $\left(14^{\circ} \mathrm{N}, 80^{\circ} \mathrm{E}, 5.5^{\circ} \mathrm{N}\right.$ dip latitude) during January-March, 1993 to observe ionospheric plasma depletions through $630 \mathrm{~nm}$ and $777.4 \mathrm{~nm}$ night glow emissions. Strong plasma depletions were observed only on four nights viz., 14, 17, 19 and 21 February, 1993. Except the 17 February, which was a magnetically disturbed day, all the other nights pertained to magnetically quiet period. A number of plasma depletion parameters such as, degree of depletion, east-west extent, tilt with respect to the geomagnetic field, inter-depletion distance, drift velocity and plasma enhancements or brightness patterns were estimated. Some of the important results are: (a) It was found that the east-west extent of plasma depletions varied with the degree of depletion; for the $630 \mathrm{~nm}$ images the degree of depletion ranged between 6-9\% per $100 \mathrm{~km}$ east-west extent and for $777.4 \mathrm{~nm}$ images it was $3 \%$ per $100 \mathrm{~km}$ east-west extent, (b) The average inter-depletion distance (IDD) was in the range of $1500 \pm 100 \mathrm{~km}$ during the magnetically disturbed period and $740 \pm 60 \mathrm{~km} \mathrm{during}$ quiet periods. This is suggestive of gravity wave modulation of the bottom side of the F-region. While the large scale gravity waves $(1500 \pm 100 \mathrm{~km})$ of auroral origin could be responsible during magnetically disturbed period, smaller scale gravity waves $(740 \pm 60 \mathrm{~km})$ having their origin in the lower atmosphere could produce initial perturbation in the bottom side of the F-region, (c) Plasma depletions are observed to have an eastward tilt in the range of 10-15 with respect to the geomagnetic field. It has been suggested here that these tilts are associated with the variation of plasma drift with altitude, (d) plasma depletions are observed to be moving eastwards with drift velocities in the range of 40-190 $\mathrm{ms}^{-1}$, and (e) Strong plasma enhancements or brightness patterns were observed on three nights. The degree of enhancement was by a factor of 1.4-3.8. These enhancements lasted for more than 15 minutes. Although, prima facie, these observations look similar to the transient brightness wave reported by Mendillo et al. (1997a), the high degree of enhancement and an extended duration of more than 15 minutes, observed in the present case, need to be understood.
\end{abstract}

\section{Introduction}

Ionospheric plasma depletions, bubbles or holes represent strong decrease of F-region plasma density over large spatial scales. These are localized depletions in plasma density with spatial dimensions of the order of a few tens to a few hundred kilometers across the magnetic field. Hereafter, the term plasma depletion will be used to represent such large decrease in plasma density. These large-scale structures represent the outer scale of the equatorial spread F (ESF) irregularity spectrum. As the outer scale of ESF structures governs the subsequent development and characteristics of the irregularity spectrum, a full description of plasma depletions could lead to a better understanding of the generation of ESF irregularities.

Plasma depletions were discovered as 'ion density biteouts' by Hanson and Sanatani (1973) using in-situ satellite borne probes. These localized, irregular depletions in ion density were subsequently studied by others using insitu techniques (Kelley et al., 1976; McClure et al., 1977; Benson and Brinton, 1983; Jahn et al., 1997; Singh et al.,

Copy right(C) The Society of Geomagnetism and Earth, Planetary and Space Sciences (SGEPSS); The Seismological Society of Japan; The Volcanological Society of Japan; The Geodetic Society of Japan; The Japanese Society for Planetary Sciences. 1997b). Plasma depletions are mostly aligned to the geomagnetic field with plasma density decreases up to about 3 orders of magnitudes or $99.9 \%$ of the background (McClure et al., 1977). These depletions are generally produced over geomagnetic equator and they convect upward at large velocities through the F layer peak to the topside ionosphere, reaching altitudes as high as $1200 \mathrm{~km}$ or more (Woodman and LaHoz, 1976). Some examples of very fast equatorial bubbles have also been reported by Hanson et al. (1997). Subsequently, they diffuse down the magnetic field lines to lower altitudes at low latitudes. The plasma inside the depletions has been found to have velocities both perpendicular and parallel to the geomagnetic field (Hanson and Bamgboye, 1984; Aggson et al., 1992). The post-sunset equatorial F layer can become unstable under the influence of any disturbance produced by gravity waves, neutral winds or some other source and can generate plasma irregularities through Rayleigh-Taylor instability (RTI) (Hysell et al., 1990; Singh et al., 1997a). Steep plasma density gradients produced by the primary long wavelength Rayleigh-Taylor mode, create a condition which leads to the hierarchy of plasma instabilities giving rise to smaller scale irregularities.

Plasma depletions, which are generated through RTI process, manifest as regions of low intensity in the night airglow 
images. Thus the morphology and the dynamics of these field aligned transequatorial ionospheric plasma depletions can be monitored through ground based observations of the intensities of various ionospheric night airglow emissions. Atomic oxygen emissions, which are produced as a result of F-region recombination processes, are very important diagnostic tools to study large scale F-region irregularities, such as plasma depletions. The OI emissions at $777.4 \mathrm{~nm}$ and $630 \mathrm{~nm}$ are particularly suitable for ground based mapping of plasma depletions when they are located around $F_{2}$ peak and around $250 \mathrm{~km}$, respectively. The $630 \mathrm{~nm}$ airglow line is emitted by $\mathrm{O}\left({ }^{1} \mathrm{D}\right)$ atoms which are produced by the dissociative recombination of $\mathrm{O}_{2}{ }^{+}$with electrons during nighttime (Hays et al., 1978). The $777.4 \mathrm{~nm}$ emission, first discovered by Weil and Joseph (1970), results mainly from the radiative recombination of $\mathrm{O}^{+}$and electrons in the ionospheric F-region.

Equatorial plasma depletions have been studied earlier using the all sky optical imaging technique (Weber et al., 1978; Mendillo and Baumgardner, 1982; Rohrbaugh et al., 1989; Sinha et al., 1991; Mukherjee et al., 1993; Sahai et al., 1994; Sinha et al., 1996; Mendillo et al., 1997a, b; Taylor et al., 1997; Tinsley et al., 1997; Bittencourt et al., 1997; Fagundes et al., 1997, 1999). Bulk of the observations using the imaging technique have come from the American and $\mathrm{Pa}-$ cific sectors. This paper presents some novel features related to plasma depletions in the Indian sector.

\section{Observations}

An all sky optical imaging system was operated at SHAR $\left(14^{\circ} \mathrm{N}, 80^{\circ} \mathrm{E}, 5.5^{\circ} \mathrm{N}\right.$ dip latitude) from January to March 1993 to photograph ionospheric plasma depletions. During this period, a ground-based ionosonde was operated at SHAR and VHF scintillations were recorded at Ahmedabad, SHAR and Waltair using the $244 \mathrm{MHz}$ beacon onboard the geostationary satellite FLEETSAT $\left(73^{\circ} \mathrm{E}\right)$. Details of the imaging system developed at the Physical Research Laboratory (PRL), occurrence of spread $\mathrm{F}$ during this campaign and manifestation of irregularities in VHF scintillation records taken from stations near the geomagnetic equator to the crest of equatorial anomaly were reported earlier (Sinha et al., 1996). Strong depletions were observed in February. During this month, out of 10 nights of continuous observations, depletions were seen on 4 nights viz. 14, 17, 19 and 21 February 1993. There was a rocket flight on 19 February, 1993 from SHAR and hence the whole rocket range was lighted with the result that only a few images could be taken on the night of 19 February, 1993 (Sridharan et al., 1997). Sinha et al. (1996) have reported some of the observations obtained on the night of 21 February 1993. Some new and interesting features of plasma depletions, seen in the airglow images during these four nights, which had intense ESF activity, are presented here.

\section{Image Processing Procedure}

All the airglow images, which were recorded on $35 \mathrm{~mm}$ film were digitized using CCD-based digitizing system yielding an array of $512 \times 512 \times 8$ bits. In order to take care of the image intensifier noise, flat fielding and variable exposure, following image-processing procedures were used. Using a light emitting diode (LED) as a light source, a condensing lens system, to diffuse the light uniformly, and using an unexposed film as a screen, a number of frames were grabbed. These frames represented flat field frames. An average of 10 such flat field frames was taken to generate the "master flat field frame" for the CCD camera employed for digitizing. For generating a frame for the removal of the noise of the image intensifier, the front cover of the fish eye lens was closed and 30, 60 and $120 \mathrm{~s}$ exposures were taken before, during and after the observing period. All such frames having same exposure time were averaged and a "master noise frame" for the image intensifier noise was generated for each of the exposure times. The data frames were then normalized with the "master flat field frame", to remove the non-uniformities of the illumination of the digitizing system and with the "master noise frame", to remove the image intensifier noise. Thus a series of data frames was obtained for a particular exposure time. Next, all these frames were averaged to generate a "background frame". This "background frame" was subtracted from the data frames to remove all the stationary features such as the station illumination, building lights, etc. and thus enhancing the non-stationary features such as the plasma depletions. As no calibration with the standard source was performed, the airglow intensities of all the images reported here are only relative values.

As mentioned earlier, all the images were grabbed in $512 \times$ $512 \times 8$ bit format. The size of the image at the image intensifier was a circle of $23 \mathrm{~mm}$ diameter. If the imager is mounted exactly vertically, the center of the image corresponds to local zenith. As one moves away from the center of the image, the field of view increases non-linearly, becoming $\pm 90^{\circ}$ at both edges. Thus using the response curve of the fish eye lens, supplied by the manufacturers, one can calculate the zenith angle of a particular pixel as a function of the distance from the center of the image. Next, assuming that $630 \mathrm{~nm}$ and $777.4 \mathrm{~nm}$ emissions come from layers which have their centroids approximately at $250 \mathrm{~km}$ and $350 \mathrm{~km}$, respectively, the exact location of any particular pixel can be determined uniquely. In this way one can determine the horizontal distances in the image. In view of the facts a) that the actual image of the sky made by the optical system was slightly smaller than the CCD array size and b) that the image is compressed near the edges of the FOV in case of a fish eye lens, the usable image data is only 300 pixels, i.e., $256 \pm 150$ pixels. As, for the present observations, the imager was mounted exactly vertically, the center of the image, which has the pixel number 256 both in the E-W and N-S direction, corresponds to the local zenith. In order to estimate plasma depletion parameters, viz., the location of depletions and enhancements, degree of depletion, east-west extent of the depletions and inter-depletion distance, eight pixels in the N-S direction, around the 256th pixel, were averaged for each pixel in the horizontal (E-W) direction. This gave the variation of airglow intensity (in relative units) in the east-west direction along the centre of the image at the zenith. The eastern and western edges of plasma depletions/enhancements were then identified from these E-W scans and the middle point of both these edges was termed as the exact location of that particular depletion. Inter-depletion distances between two depletions were calculated with respect to the centers of the individual 

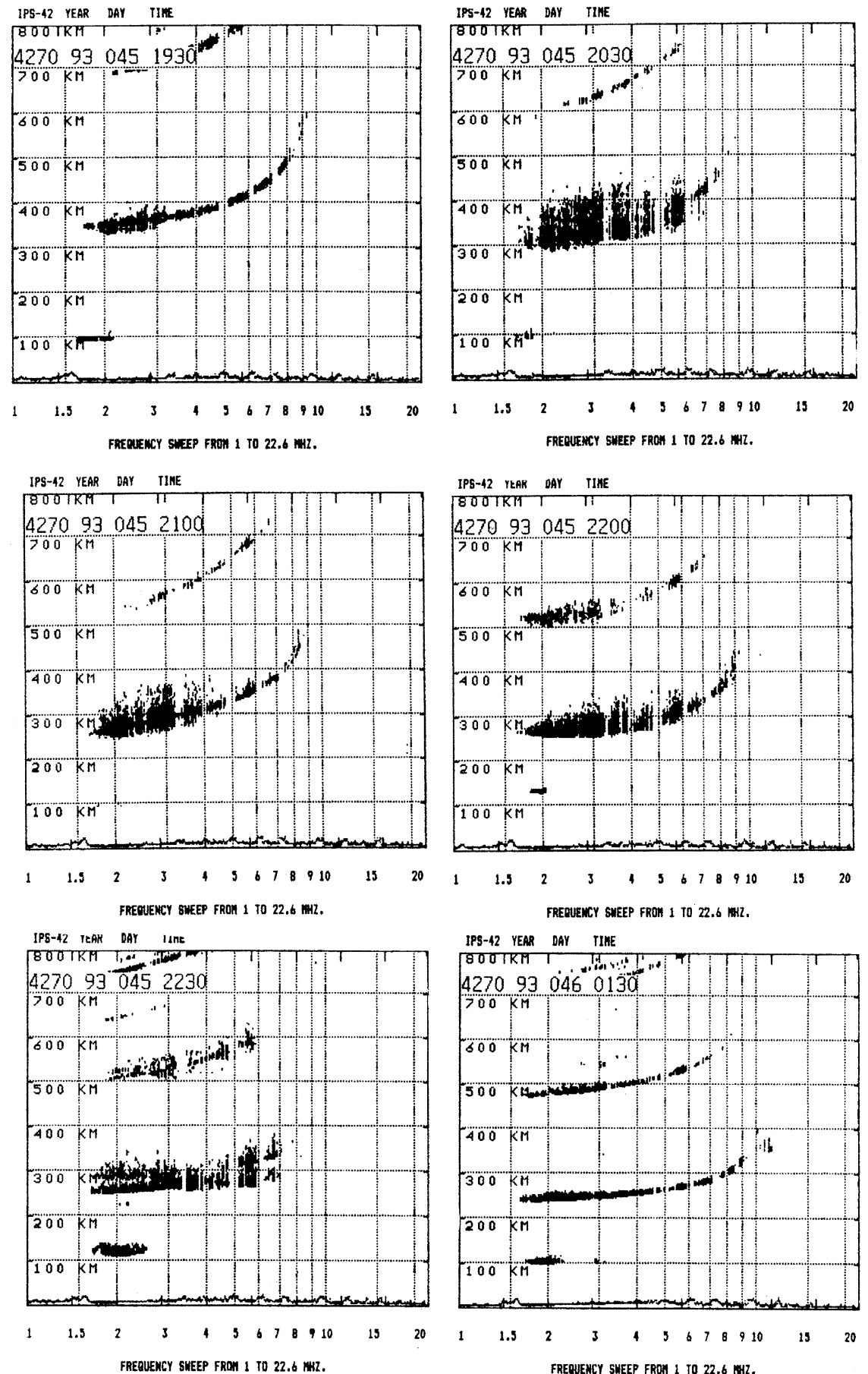

Fig. 1. Sequence of ionograms over SHAR at 1930, 2030, 2100, 2200, 2230 and 0130 LT during the night of 14/15 February, 1993.

depletions. As we have calculated the depletion parameters from the E-W scans of the airglow intensity through local zenith, no latitudinal (N-S) effects will show up.

\section{Results}

Spread F activity over SHAR during the observation campaign was monitored using a KEL ionosonde. All the four nights for which observations were made $(14,17,19$ and 21 February, 1993) were spread F nights. One such sample of ionograms taken on the night of 14/15 February, 1993 is shown in Fig. 1. It is observed that the first trace of diffuse echoes appeared around 1930 LT and by 2030 LT the spread
F was well developed as seen by the intense spread of echoes in the ionogram. ESF persisted up to $0115 \mathrm{LT}$ after which the ionogram traces were clean. Intense spread $\mathrm{F}$ activity was present on the night of 17, 19 and 21 February, 1993 also. All the nights of observations, except 17 February, 1993, were magnetically quiet nights. On 17 February, 1993, there was a strong solar flare at $1040 \mathrm{UT}$, wherein, the solar Xray flux in 1-8 A increased by a factor of about 28 . This flare was followed by a strong magnetic storm. The three hourly magnetic index, $K_{p}$, just before and during the period of observations was $7^{-}$and $6^{-}$, respectively (Table 1 ). 
Table 1. The range of inter-depletion distance (IDD), the average IDD and 3 hourly $K_{p}$ index of magnetic activity during $1730-2030$ LT and 2030-2330 LT for the plasma depletions observed in $630 \mathrm{~nm}$ and $777.4 \mathrm{~nm}$ on 14, 17, 19 and 21 February, 1993.

\begin{tabular}{cccccc}
\hline \multirow{2}{*}{ Date } & \multirow{2}{*}{ Emission $(\mathrm{nm})$} & \multicolumn{2}{c}{3 Hourly $K_{p}$ Index } & \multicolumn{2}{c}{ IDD $(\mathrm{km})$} \\
& & $1730-2030 \mathrm{LT}$ & $2030-2330 \mathrm{LT}$ & Range & Average \\
\hline 14 Feb. 1993 & 630.0 & $1^{+}$ & $1^{-}$ & $424-1056$ & 682 \\
17 Feb. 1993 & 630.0 & $7^{-}$ & $6^{-}$ & $1480-1600$ & 1562 \\
19 Feb. 1993 & 630.0 & $1^{+}$ & 1 & $711-844$ & 800 \\
21 Feb. 1993 & 630.0 & 4 & 5 & $776-944$ & 865 \\
21 Feb. 1993 & 777.4 & 4 & 5 & $496-1008$ & 794 \\
\hline
\end{tabular}

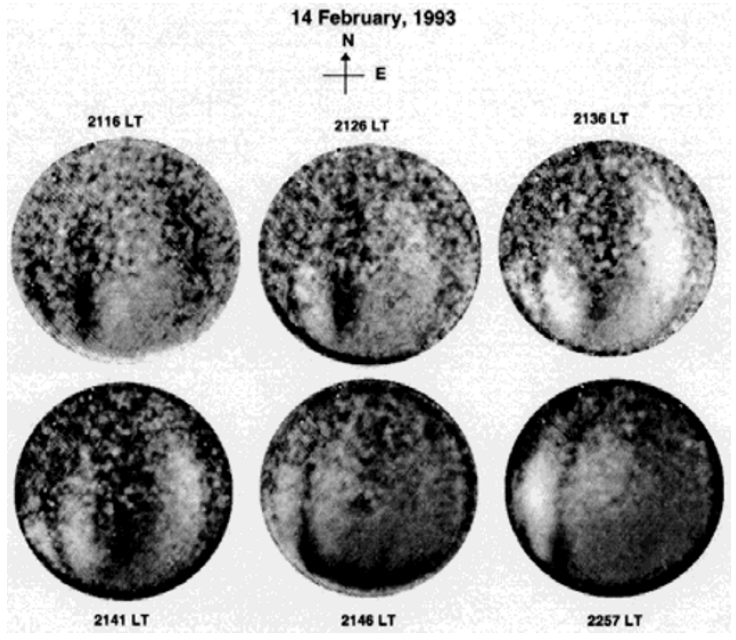

Fig. 2. Sequence of $630 \mathrm{~nm}$ airglow images taken on the night of 14 February, 1993 over SHAR. The arrow points towards geomagnetic north.

\subsection{Plasma depletions}

Figure 1 shows a series of ionograms taken from SHAR on the night of 14/15 February, 1993. As seen in Fig. 1, the spread F activity started around 1930 LT on 14 February, 1993 and disappeared around 0130 LT. The first $630 \mathrm{~nm}$ image, in which plasma depletions could be clearly identified, was recorded at 2116 LT. Several plasma depletions could be seen in images recorded up to 2257 LT, beyond which depletions could not be seen in the images. Figure 2 displays the $630 \mathrm{~nm}$ airglow images obtained on 14 February 1993 at $2116,2126,2136,2141,2146$ and 2257 LT. Dark region represents low airglow intensity and are thus associated with regions where electron density is depleted relative to the background. At 2116 hrs LT three depletions are clearly seen, two on the western side and one on the eastern side. At 2126 LT all the three depletions have moved eastwards and the depletion on the eastern side has weakened. The central depletion becomes deeper i.e. the airglow intensity decreases significantly for this depletion, and it is flanked on both sides by very extended regions of enhanced airglow intensity. Subsequently, airglow enhancements occupy more regions in the images. At 2136 and $2141 \mathrm{LT}$, enhancements around both the depletions, became much brighter. At 2146 LT, the enhancement around the western depletion had become less

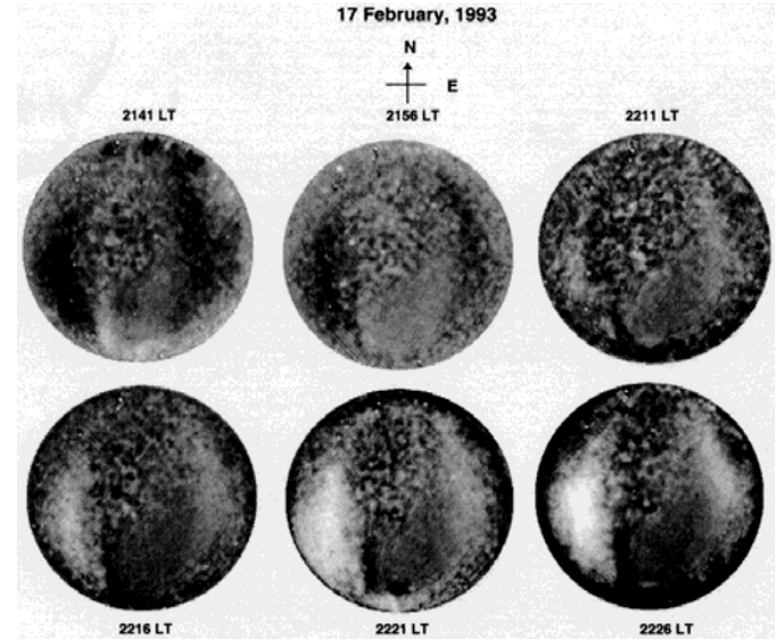

Fig. 3. Sequence of $630 \mathrm{~nm}$ airglow images taken on the night of 17 February, 1993 over SHAR. The arrow points towards geomagnetic north

pronounced. At 2257 LT, although the depletion had weakened, the enhancements on both sides became prominent once again.

Figure 3 shows the development and movement of plasma depletions on the night of 17 February 1993. Unlike the images shown earlier, depletions observed on the night of 17 February 1993 are very much extended in the east-west direction. The region surrounding the depletion shows an increase of intensity from 2216 LT onwards. As the depletions observed on this night were quite extended, the inter-depletion distance was also large and ranged between $1500 \mathrm{~km}$ and $1600 \mathrm{~km}$. Another sequence of three images taken on the night of 19 February, 1993, (not shown here) also showed the presence of two depletions flanked by enhancements on either side.

On the night of 21 February, 1993, observations could be started only at $2200 \mathrm{LT}$ due to unsuitable conditions for imaging. Airglow depletions at $630 \mathrm{~nm}$ were present right from the starting of the observations, became prominent around 2256 LT, were strongest at 2346 LT and disappeared by 0100 LT. Few examples of pronounced depletions, as seen in $630 \mathrm{~nm}$ images, at 2256, 2316, 2326, 0006, 0016 and 0021 LT during this night are shown in Fig. 4(a).

On the same night, airglow depletions at $777.4 \mathrm{~nm}$ emis- 


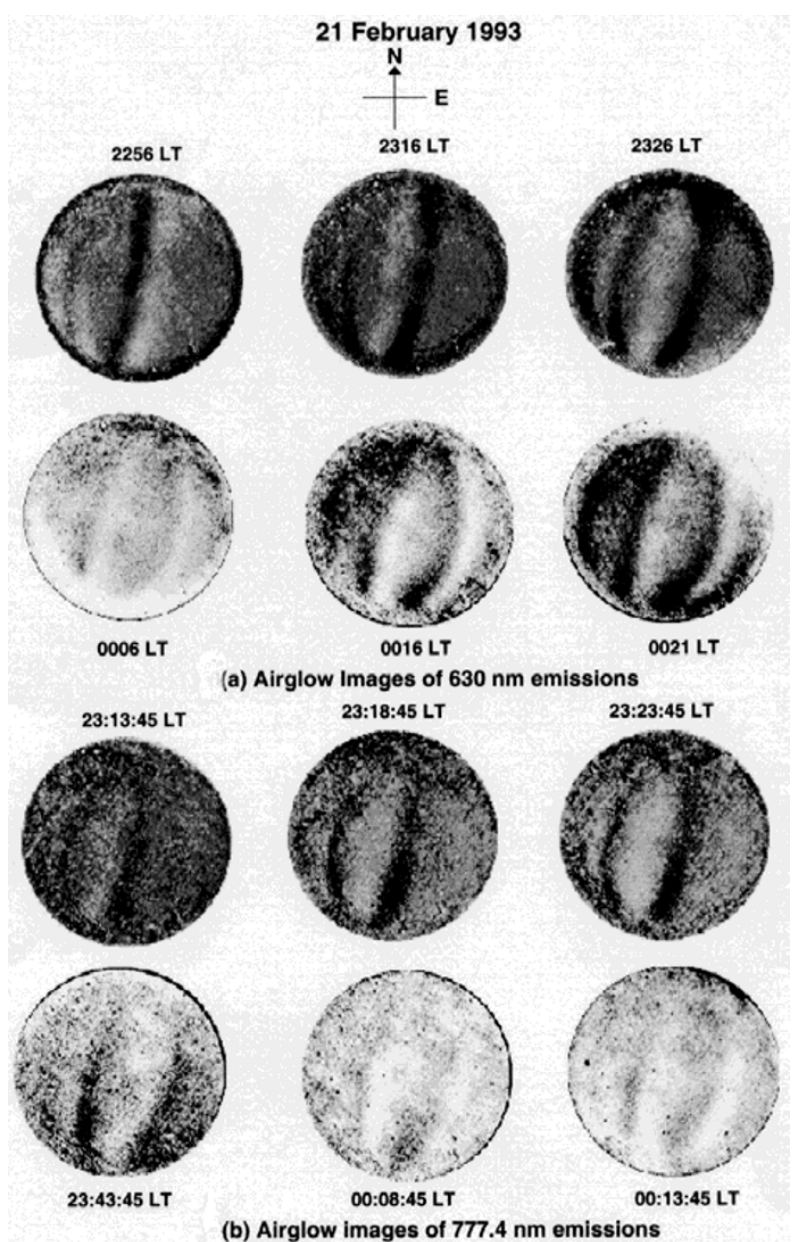

(b) Airglow images of $777.4 \mathrm{~nm}$ emissions

Fig. 4. Sequence of airglow images taken on the night of 21 February, 1993 over SHAR (a) $630 \mathrm{~nm}$ images at 2256, 2316, 2326, 0006, 0016 and 0021 LT and (b) $777.4 \mathrm{~nm}$ images at 23:13:45, 23:18:45, 23:23:45, 23:43:45, 00:08:45 and 00:13:45 LT. The arrow points towards geomagnetic north.

sion, were also observed right from $2200 \mathrm{LT}$ and some of the prominent ones are shown in Fig. 4(b). The overall intensity of $777.4 \mathrm{~nm}$ emission is smaller than $630 \mathrm{~nm}$ emission. The presence of very weak depletions can be seen in $777.4 \mathrm{im}$ ages at 23:13:45 LT. These depletions develop with time and by around 23:43:45 LT two depletions are seen very prominently and both of these are flanked by enhanced airglow intensity on either side of both the depletions. After the midnight the depletions start becoming weak and no significant depletion can be seen beyond 00:13:45 LT. An important feature which was observed on this night was the sudden increase in the airglow intensity in the whole image at 0006 LT, which took shape of a brightness wave at 0016 LT, before weakening at $0021 \mathrm{LT}$. Similar brightening of a very large part of the field of view was observed in $777.4 \mathrm{~nm}$ images at 00:08:45 LT. But these enhancements were slightly smaller in magnitude than those observed on 14 and 17 February, 1993.

Figure 5 shows a sample image obtained at 2251 LT in $630 \mathrm{~nm}$ along with a 3 -d surface map which provides a unique tool for studying the modulations in the bottom side of the F-region. This image contains a very prominent depletion, which appears as a dark band in the centre. This depletion
21 February 1993

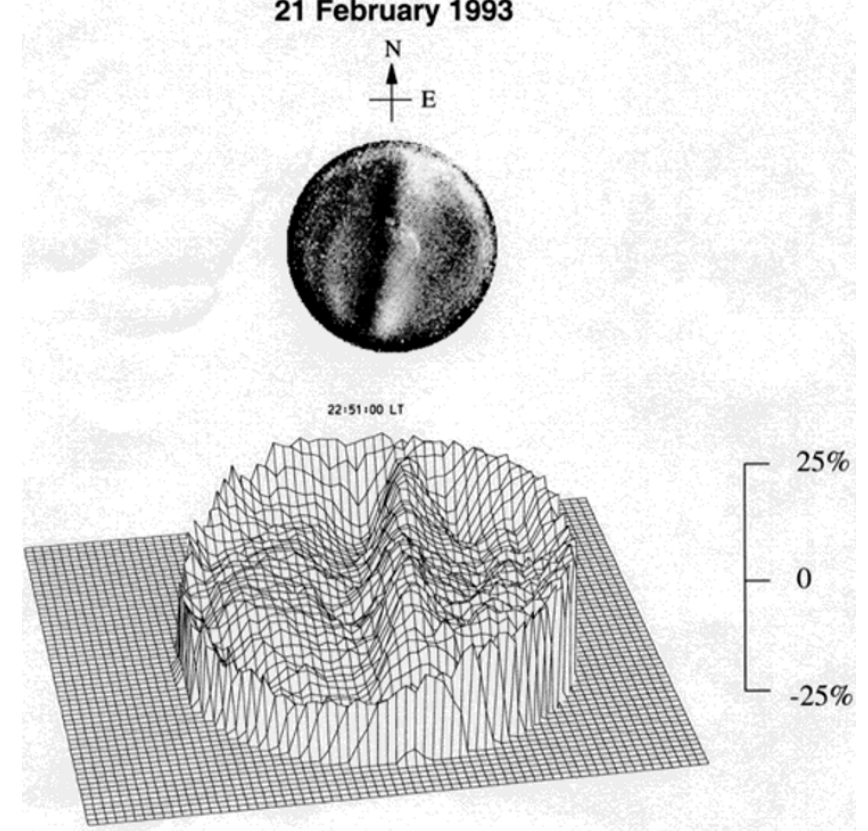

Fig. 5. $630 \mathrm{~nm}$ image having one plasma depletion taken at $2251 \mathrm{LT}$ from SHAR on the night of 21 February, 1993 (top) and 3-D surface map of the same image showing the degree of depletion (bottom). The arrow points towards geomagnetic north.

and a large enhancement on the eastern side can be seen much more clearly in the surface plot in the same figure. Table 1 gives the range of inter-depletion distance and its average value as observed in $630 \mathrm{~nm}$ images during all the four observing nights and in $777.4 \mathrm{~nm}$ images during the night of 21 February, 1993. Table 1 also shows the three hourly values of the magnetic index, $K_{p}$, during the period of observation (2030-2330 LT) and in the previous epoch (1730-2030 LT).

A very interesting feature noticed from the images is that the depletions are not aligned to the geomagnetic field but have an eastward tilt, which varies between $10-15^{\circ}$. These tilts can be seen very clearly in $630 \mathrm{~nm}$ and $777.4 \mathrm{~nm}$ images shown in Fig. 4. Similar tilts were present in images obtained on the other nights also.

\subsection{East-west extent and degree of depletion}

Multiple depletions were seen clearly on nights of 14, 17, 19 and 21 February, 1993. These depletions were having varying degree of depletion. The east-west extent of all depletions seen at zenith over SHAR was calculated as mentioned in Section 3 and the same is plotted as a function of degree of depletion with respect to the background in Fig. 6, for $630 \mathrm{~nm}$ and $777.4 \mathrm{~nm}$ images. One of the interesting observations is that the east-west extent of the depletions is found to vary with the depletion depth. Shallower depletions appear to be associated with smaller zonal width as compared to steep depletions. A straight line fit to all the curves, shows that for the $630 \mathrm{~nm}$ images the degree of depletion ranges between 6 to $9 \%$ per $100 \mathrm{~km}$ east-west extent and for $777.4 \mathrm{~nm}$ images, where the scatter is slightly more, it is about $3 \%$ per $100 \mathrm{~km}$ east-west extent. Thus regions having high degree of depletions are observed to be associated with larger depletion widths as compared to shallower depletions. This appears to 


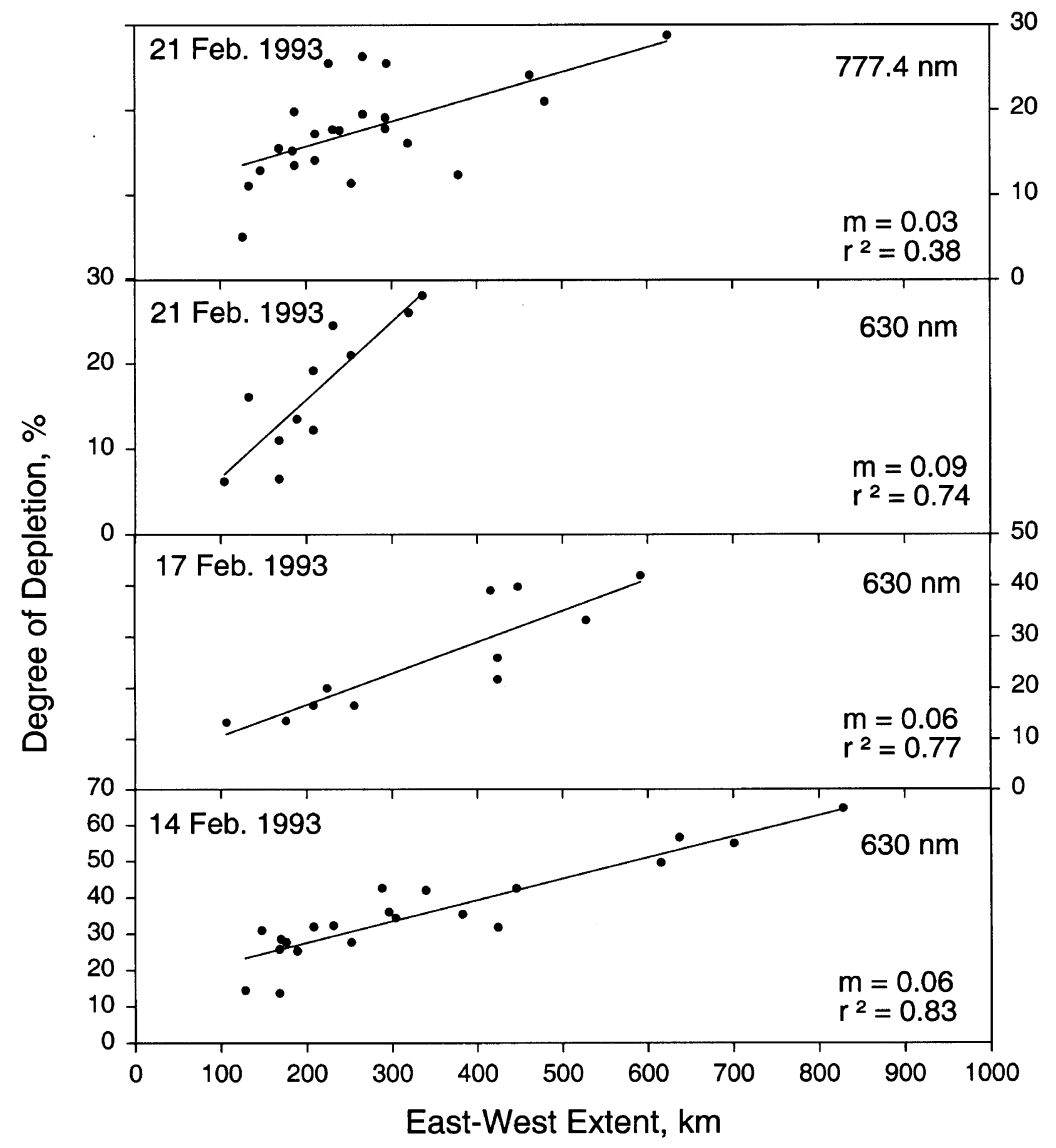

Fig. 6. Variation of the degree of depletion with the east-west extent of plasma depletions observed in $630 \mathrm{~nm}$ images on 14,17 and 21 February, 1993 and in $777.4 \mathrm{~nm}$ on 21 February, 1993. Slope of the straight line, $\mathrm{m}$, and the square of the correlation coefficient, r, are also shown for each curve.

be the manifestation of the fact that deeper depletions are characterized by large amplitudes and represent well developed irregularities, while shallower depletions depict weaker irregularities, which are in their formative stages.

\subsection{Plasma enhancements / brightness patterns}

East-west scans of relative airglow intensity through local zenith for the images at 2216, 2221, and 2226 LT on 17 February, 1993 are shown in Fig. 7. First pixel in Fig. 7 represents the western most part of the image and the last pixel represents the eastern part. On the night of 17 February, 1993, smaller enhancements are first seen at 2216 LT, 1993 around pixel numbers 49 and 232. At $2216 \mathrm{LT}$, the relative increase in the intensity for the enhancements on the western side (centered around 49th pixel) and on the eastern side, (centered around 232nd pixel) was by factors of 3.8 and 1.7, respectively. The western and eastern enhancements have spatial extents of $705 \mathrm{~km}$ and $486 \mathrm{~km}$, respectively and both are separated by $1464 \mathrm{~km}$. By $2221 \mathrm{LT}$, the intensities of both the enhancements increase by factors of 1.75 and 1.42 , respectively and they are characterized by east-west extents of $551 \mathrm{~km}$ and $584 \mathrm{~km}$ and are separated by $1456 \mathrm{~km}$. The enhancement seen around 2216 hrs LT was found to drift eastwards with a velocity of $160 \mathrm{~ms}^{-1}$, which decreases to $133 \mathrm{~ms}^{-1}$, by $2226 \mathrm{LT}$. The drift velocity of the eastern enhancement increases from $133 \mathrm{~ms}^{-1}$ to $160 \mathrm{~ms}^{-1}$ eastwards at $2256 \mathrm{LT}$. An increase in degree of enhancement is noticed at around $2226 \mathrm{hrs}$ LT where the relative airglow intensity increases by factors of 1.98 and 1.34 for the western and eastern enhancements, respectively. The zonal widths of these enhancements, which are separated by about $1464 \mathrm{~km}$, are $568 \mathrm{~km}$ and $665 \mathrm{~km}$, respectively. These brightness patterns also lasted for more than 15 minutes.

Enhancements in $630 \mathrm{~nm}$ airglow intensity were seen very prominently at 0006 LT and 0016 LT on the night of 21 February, 1993 (Fig. 4(a)) also. Airglow intensity in this case increased by factor of 1.5-1.8. These brightness patterns also lasted for nearly 15 minutes. Large enhancements in airglow intensity (up to a factor of 2), lasting for more than 15 minutes were also observed on the night of 14 February, 1993.

\subsection{Drift velocity of plasma depletions}

As all the observed plasma depletions displayed eastward motions throughout the night, an attempt was made to determine the eastward velocity of these depletions from the series of $630 \mathrm{~nm}$ images. For this purpose, the images were scanned in the east-west direction through zenith, to obtain a cross-section of the brightness pattern for each depletion from which the spatial shifts were determined. The error in our estimates of drift velocity was $\pm 10 \%$. Velocities were found to lie between $40 \pm 4$ and $190 \pm 19 \mathrm{~ms}^{-1}$ in the eastward direction as shown in Fig. 8. Figure 8 also shows eastward velocities of the irregularities obtained from other sources for comparison with our data. The dotted line shows zonal velocities of airglow depletions obtained during MISETA campaign (Mendillo et al., 1997a) from Arequipa, 


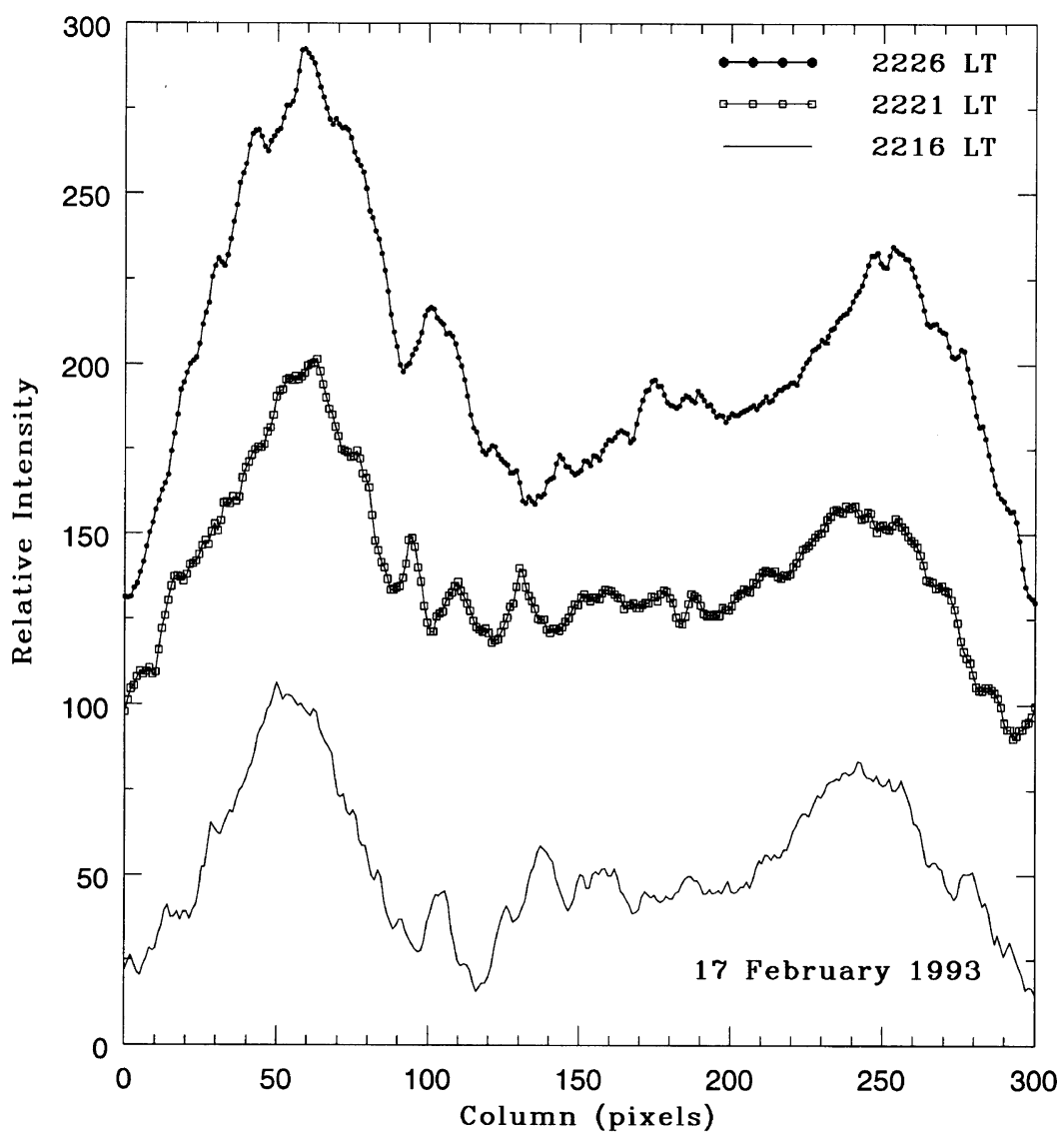

Fig. 7. East-west scans of the $630 \mathrm{~nm}$ airglow images, through zenith over SHAR, showing enhancements in airglow intensity at 2216,2221 and 2226 LT on the night of 17 February, 1993. Intensity values at 2221 and 2226 LT, have been shifted up on the ordinate axis by 50 and 100 for viewing convenience. Total east-west extent covered by 300 pixels is about $2400 \mathrm{~km}$.

Peru $\left(16.5^{\circ} \mathrm{S}, 72^{\circ} \mathrm{W}\right)$ which agrees closely with the values obtained from the drift model (Fejer, 1991) which are shown as solid line. The dashed line in Fig. 8 displays the eastward velocity obtained using from the total electron content (TEC) measurements made at Cachoeira Paulista $\left(22.7^{\circ} \mathrm{S}, 45.0^{\circ} \mathrm{W}\right.$, dip latitude $15.8^{\circ} \mathrm{S}$ ) using VHF radio beacon on GOES 3 (Abdu et al., 1985). They showed TEC fluctuations to be the manifestation of plasma bubble dynamics in the equatorial ionosphere, since they were strongly correlated with range type spread $\mathrm{F}$ and amplitude scintillations. Different scale sizes producing TEC fluctuations are expected to drift with the same east-west speed as they are colocated within a plasma depletion (Tsunoda and Towle, 1979; Szuszczewicz et al., 1980). It can be seen from the Fig. 8 that the decrease in irregularity speed with respect to the local time over SHAR is consistent with the trend seen at Cachoeira Paulista and Arequipa. However, the drift velocities obtained from our data are slightly higher than those observed at Arequipa, Peru $\left(16.5^{\circ} \mathrm{S}, 72^{\circ} \mathrm{W}\right)$ and are smaller than those observed at Cachoeira Paulista $\left(22^{\circ} \mathrm{S}, 45^{\circ} \mathrm{W}\right)$.

\section{Discussion}

\subsection{Inter Depletion Distance (IDD)}

It has been mentioned earlier that $630 \mathrm{~nm}$ emission originates from the bottomside of the $\mathrm{F}$ layer and airglow depletions in $630 \mathrm{~nm}$ line are associated with bottomside structures in the F layer (Weber et al., 1978). Thus the 3-D surface maps of the airglow images provide a unique way for studying the modulation of the bottomside F layer. 3-D surface maps showing wave like structures are shown in Fig. 5. The distance between adjacent depletions, the inter depletion distance (IDD), is representative of the scale size of the altitude modulated F layer which, in turn, can throw light on the source responsible for the modulation of the bottomside $\mathrm{F}$ layer. IDD as observed in our data is found to vary between $400 \mathrm{~km}$ to about $1600 \mathrm{~km}$. Plumes observed in the RTI maps of radar (Tsunoda and White, 1981; Tsunoda et al., 1982; Tsunoda, 1983; Kelley et al., 1986) correspond to depletions that are usually generated near the crest of large scale upwellings. The primary plume spacing seen in the RTI maps is about $400-600 \mathrm{~km}$. However, it is to be noted that the plume spacing is derived from radar maps by assuming a mean horizontal plasma drift speed. IDD inferred from airglow images in the present study are more realistic as the images are the snapshots giving the instantaneous picture. A quick look at Table 1 shows that the average inter-depletion distance (IDD) is very large (1562 km) on 17 February, 1993, which was a highly magnetically disturbed day. On the other days of observation, the average IDD was $682 \mathrm{~km}, 865 \mathrm{~km}$ and $794 \mathrm{~km}$ in $630 \mathrm{~nm}$ images and $800 \mathrm{~km}$ in $777.4 \mathrm{~nm}$ images.

The separation between the adjacent depletions (IDD) observed by us suggests that gravity waves might be the seeding agency for generating such large scale structures as pointed 


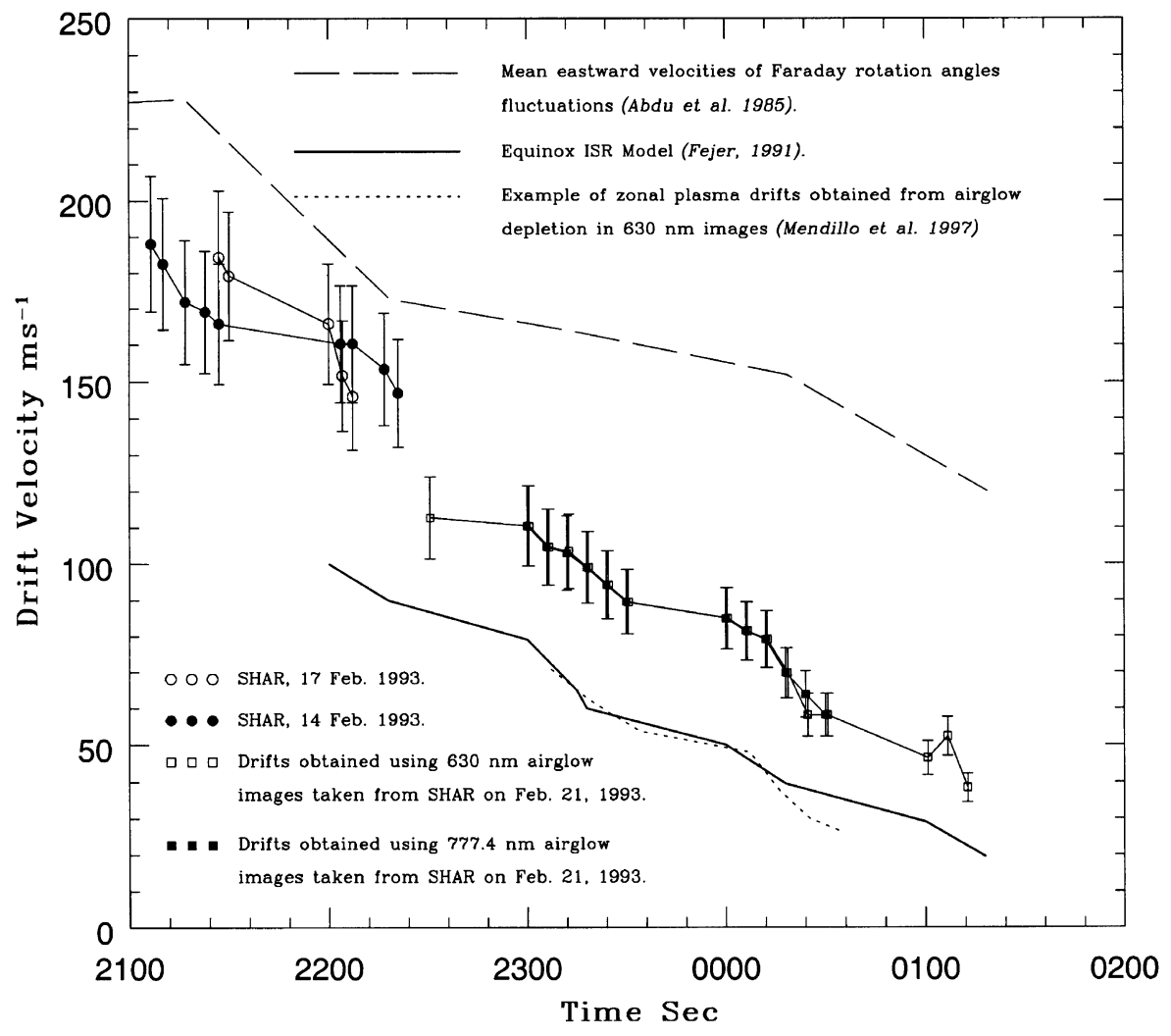

Fig. 8. Eastward drift speed of plasma depletions obtained by various techniques.

out earlier by Kelley et al. (1981) and Hysell et al. (1990). As described by Kelley et al. (1981), gravity waves responsible for producing seed perturbations for the equatorial spread $\mathrm{F}$ can have sources in the ionosphere or in the lower atmosphere. The gravity waves in the ionosphere are associated with magnetic disturbances in the auroral zone and have horizontal wavelengths in excess of $1000 \mathrm{~km}$ and periods in the range of 15-min to a few hours. The gravity waves having their sources in the lower atmosphere, generally have wavelengths smaller than $1000 \mathrm{~km}$. Kelley et al. (1981) have experimentally found the horizontal wavelength of such gravity waves to be in the range of $680 \pm 50 \mathrm{~km}$. In view of this, we feel that the inter-depletion distance of 1480-1600 km, observed by us on 17 February, 1993, which was a magnetically disturbed day, could be an experimental evidence of modulation of the bottom side electron density of the F-region by gravity waves, having their origin in the auroral region. The average inter-depletion distance range of $682-865 \mathrm{~km}$ observed on 14, 19 and 21 February, 1993, which were magnetically quiet days, appears suggestive of the modulation by gravity waves having their origin in the lower atmosphere. The wavelengths of 682 to $865 \mathrm{~km}$, observed on the quiet days, are well within the permissible solutions of the gravity wave dispersion relation as shown in Fig. 6 of Kelley et al. (1981).

There have been a number of other observations which point to the gravity wave initiation of the seed perturbation of the equatorial spread F. F-region gravity wave airglow signatures were imaged at Arecibo $\left(18^{\circ} \mathrm{N}, 65^{\circ} \mathrm{W}\right.$, dec. $\left.\approx 11^{\circ} \mathrm{W}\right)$ by Nottingham et al. (1994) and Mendillo et al. (1997b) and at Cachoeira Paulista $\left(22^{\circ} 41^{\prime} \mathrm{S}, 45^{\circ} 00^{\prime} \mathrm{W}\right.$, dip $\left.28^{\circ} \mathrm{S}\right)$ by Sobral et al. (1997). Singh et al. (1997a) presented examples of plasma bubble development from wavy ion density structures in the bottomside F layer using Atmosphere Explorer E data. The wavy structures mostly had east-west wavelengths of $150-800 \mathrm{~km}$ with a exception of $3000 \mathrm{~km}$ in one case. Singh et al. (1997a) found that in a fully developed equatorial spread $F$ case, east-west wavelengths varying between $0.5 \mathrm{~km}$ to $690 \mathrm{~km}$ occurred simultaneously and they presented observations showing that the spacing between bubble patches appeared to be determined by the wavelengths present in the precursor wave structure.

\subsection{Tilts}

As mentioned earlier, our airglow images showed depletions which exhibited eastward tilts. Initial results from airborne measurements conducted within a few degrees, of the magnetic equator (Weber et al., 1978; Buchau et al., 1978) revealed that depletions were N-S aligned close to the geomagnetic equator but a skewness was observed for depletions far from the equator. In a subsequent study from a region north of Ascension Island $\left(7.9^{\circ} \mathrm{S}, 14.4^{\circ} \mathrm{W}\right.$, dip lat. $\left.16^{\circ} \mathrm{S}\right)$, Weber et al. (1980) observed westward tilts near the poleward ends of the depletions. Subsequent ground based studies, using all sky imaging system (Mendillo and Baumgardner, 1982; Mendillo and Tyler, 1983), showed that the depletions observed from Ascension Island display westward tilts which seemed to be the optical manifestation of the westward tilts of the plumes recorded by incoherent scatter radar (Woodman and LaHoz, 1976; Tsunoda, 1980) and by in-situ probes (McClure et al., 1977). 
Woodman and LaHoz (1976) proposed that an eastward neutral wind blowing through a depleted region could polarize the depletion so that it drifts eastward with velocity less than the ambient $\mathrm{E} \times \mathrm{B}$ eastward drift. Thus, relative to the background ionosphere, the depletions drift westward as they rise, which accounts for the westward tilts of the plumes. Simulation studies by Zalesak et al. (1982) showed westward tilts of the depletions to be due to the assumed decrease of the flux-tube integrated Pedersen conductivity above $h_{\max }\left(F_{2}\right)$ with increasing altitude. This decrease leads to a shear in eastward plasma drift, which is responsible for the westward tilt of the simulated bubble structure. An alternative mechanism was suggested by Anderson and Mendillo (1983), which indicate that westward tilts are associated with eastward plasma drifts that decrease with altitude above $F_{2}$ peak and this shear results from an latitudinal decrease in zonal wind.

It is known that the eastward zonal wind results in the development of vertically downward polarization electric fields, through F-region dynamo, which in turn causes Fregion plasma drift. Thus, an increase in zonal wind with altitude will result in an increase in the eastward plasma drift with altitude. Haerendal (1980) deduced westward plasma flow in the lower F-region which reverses to eastward at higher levels, from vapor cloud release experiments, whereas radar measurements of plasma irregularities by Kudeki et al. (1981) and Tsunoda et al. (1981) have shown positive shears, velocity increasing with altitude. Eastward tilts seen in our data suggest that tilts might be associated with the variation of plasma drifts with altitude, thus supporting the mechanism proposed by Anderson and Mendillo (1983). This is further strengthened by the evidence of the existence of positive shears in the zonal winds with altitude which have been obtained using barium vapor release method during the onset time of ESF (Raghavarao et al., 1987; Sridharan et al., 1997). Ionization hole campaign (Sridharan et al., 1997) conducted from SHAR on 19 February, 1993, revealed that zonal winds exhibit a positive shear of $2.2 \mathrm{~ms}^{-1} \mathrm{~km}^{-1}$. Optical imaging results of $630 \mathrm{~nm}$ obtained from SHAR during the same night, but at a slightly later time, also display eastward tilts suggesting the existence of latitudinal increase in plasma drifts.

\subsection{Drift velocity}

The eastward drift velocity determined from our data lies in between the values at Cachoeira Paulista and Arequipa. This appears to be a manifestation of possible existence of a latitudinal variation in the zonal velocities which when projected in the equatorial plane would manifest as shear in the velocity. Abdu et al. (1985) reached the same conclusion by comparing zonal velocities obtained from TEC fluctuations with those derived from Jicamarca radar and VHF scintillations over Natal. Koparkar and Rastogi (1985) inferred eastward velocities of drifting patches using the scintillations of SIRIO and FLEETSTAT satellite signals to be in range of $100-150 \mathrm{~ms}^{-1}$. Mendillo and Baumgardner (1982) studied the local time variation of drift velocity of $630 \mathrm{~nm}$ airglow depletion patches over Ascension Island $\left(7.5^{\circ} \mathrm{S}\right)$ and found that the drift velocity decreased from $190 \mathrm{~ms}^{-1}$ to $80 \mathrm{~ms}^{-1}$ at 0100 LT. Taylor et al. (1997) found drift velocities of the depletions to be approximately $80-100 \mathrm{~ms}^{-1}$ eastwards, prior to local midnight and reduced to a minimum of 30 $50 \mathrm{~ms}^{-1}$ in the morning hours. There was no indication of drift reversal in our data, which has been observed by Weber et al. (1978) and Taylor et al. (1997). Taylor et al. (1997) suggested this reversal to be related to the reversals in the F-region dynamo winds, possibly due to impulsive magnetic activity earlier in the evenings.

\subsection{Plasma enhancement / brightness patterns}

Plasma enhancements or brightness patterns were observed on three nights but the two events observed on the nights of 14 and 17 February were more intense and looked similar to a brightness wave. These feature appeared both in the southwest and north-east of zenith and were seen to drift eastwards, exiting from north east side of zenith. The brightness patterns persisted for a few tens of minutes. It is very interesting to note that the degree of plasma enhancements, on 14 and 17 February was much higher than the degree of depletion seen on these and other nights. The degree of enhancement was by a factor, which ranged between 1.4 and 3.8, whereas the maximum degree of depletion recorded in all the nights was only about $65 \%$. Recently 'brightness wave' was reported during MISETA campaign (Mendillo et al., 1997a) which appeared as transient airglow structures seen in the airglow images recorded at Arequipa, Peru $\left(16.4^{\circ} \mathrm{S}\right)$. These were interpreted in terms of an anomaly associated with the thermal behavior of the upper atmosphere. Mendillo et al. (1997a, b) concluded that the brightness waves results from airglow produced by poleward winds generated by midnight pressure bulge, which is produced due to midnight temperature maximum (MTM). The brightness patterns observed by us could, in principle, be produced by similar mechanism. But in absence of simultaneous measurements of neutral temperature, it is not possible to guess whether such large enhancements, by a factor as large as 3.8 , could be produced by the poleward winds alone. The reasons for an extended time period for the brightness patterns seen in our data, unlike the transient wave like behavior observed by Mendillo et al. (1997a), and for sudden brightening of the entire image, have yet to be understood.

\section{Summary}

This paper has presented some new features of plasma depletions, which are large-scale structures associated with the phenomenon of equatorial spread-F. The characteristics of these depletions were studied over SHAR using an all-sky optical imaging instrument developed in PRL. Some important features of plasma depletions are: On 17 February, 1993, which was associated with a strong magnetic storm, IDD increased by a factor of 2 and became as high as $1600 \mathrm{~km}$. This suggests that the gravity waves of auroral origin could be responsible for the modulation of bottom side of the Fregion as suggested earlier by Kelley et al. (1981) and by Hysell et al. (1990). On the other three nights, where no magnetic disturbances were present, average IDD was in the range of $740 \pm 60 \mathrm{~km}$, suggesting that gravity waves having their origin in the lower atmosphere could be responsible for perturbing the bottom side during quiet periods.

A very interesting feature noticed is the tilt of plasma depletions which lies in the range of 10 to 15 degrees towards the east relative to geomagnetic field. It is to be noted that 
the magnetic declination over SHAR is $\sim 2.5^{\circ} \mathrm{W}$. However, this is in contrast to the earlier observations of Mendillo and Tyler (1983) which displayed westward tilts. Anderson and Mendillo (1983) tried to explain the westward tilts on the basis of eastward plasma drifts that decrease with altitude above $\mathrm{F}_{2}$ peak. We conjecture that the eastward tilts of plasma depletion seen in our data are associated with the variation of plasma drifts with altitude. This is supported by the evidence of the existence of positive shears in the zonal winds (with altitude) which have been obtained using $\mathrm{Ba}$ vapor release method at the onset time of ESF.

Multiple depletions found in the airglow images are found to have varying degree of depletions. One of the interesting observations is that the east-west extent of the depletions varies with the degree of depletion. For $630 \mathrm{~nm}$ images, the degree of depletion ranges between $6 \%$ to $9 \%$ per $100 \mathrm{~km}$ east-west extent. In the case of $777.4 \mathrm{~nm}$ images, the degree of depletion is only about $3 \%$ per $100 \mathrm{~km}$ east-west extent. The present data shows that shallower depletions are associated with smaller zonal width as compared to deeper depletions. We believe that this is the manifestation of the fact that deeper depletions, characterized by large amplitudes, represent well developed irregularities while shallower depletions are representative of onset time irregularities.

The distance between adjacent depletions, the interdepletion distance (IDD) is representative of the scale size of the initial perturbation. IDD is found to vary between $400 \mathrm{~km}$ to about $1600 \mathrm{~km}$. The separation between consecutive depletions on a magnetically disturbed night appears to be the first experimental evidence of the modulation of the bottom side of the F-region by gravity waves of auroral origin. It is also suggested that gravity waves, having their origin in the lower atmosphere, could be the seeding agency for generating modulation of the bottom side of the F-region on quiet nights.

On some nights, sudden enhancements in airglow intensity were seen very clearly in our data. This has some similarity to the 'brightness wave' observed by Mendillo et al. (1997a) during the MISETA campaign, which appeared as transient airglow structure in the airglow images and was interpreted in terms of MTM (Midnight Temperature Maximum). The important difference, the reason for which are not very clear at the moment, is that the brightness pattern seen in our data lasts for a few tens of minutes in contrast to the observations of during MISETA campaign, where only transient brightness patterns were seen.

Drift velocity of the plasma depletions was found to range between $40-190 \mathrm{~ms}^{-1}$. The drift velocity was found to be highest $\left(190 \mathrm{~ms}^{-1}\right)$ around $2100 \mathrm{LT}$ and showed a gradual decrease to about $40 \mathrm{~ms}^{-1}$ by 0100 LT beyond which the depletions became extremely weak. The general trend of the variation of drift velocity and the absolute values are in agreement with values available in the literature.

Acknowledgments. The authors are thankful to the director and the staff of SHAR Centre of ISRO, for providing all necessary facilities for conducting this experiment. Authors are grateful to the director of the Space Physics Laboratory (SPL), Trivandrum for providing the ionograms for SHAR. Mr. R. N. Misra, Mr. N. Dutt, Professor H. Chandra, Dr. Ashok Ambastha and Dr. V. V. Somayajulu provided their help very generously during all stages of this work and the same is acknowledged gratefully. This work was supported by the Physical Research Laboratory, Ahmedabad.

\section{References}

Abdu, M. A., I. J. Kantor, I. S. Batista, and E. R. de Paula, East-west bubble irregularity motion determined from spaced VHF polarimeters: Implications on velocity shear in the zonal F-region bulk plasma motion, Radio Sci., 20, 111-122, 1985.

Aggson, T. L., W. J. Burke, N. C. Maynard, W. B. Hanson, W. R. Hogey, and J. L. Saba, Electric field observations of equatorial depletions, $J$. Geophys. Res., 97, 2997-3009, 1992.

Anderson, D. N. and M. Mendillo, Ionospheric conditions affecting the evolution of equatorial plasma depletions, Geophys. Res. Lett., 10, 541544, 1983.

Benson, R. F. and H. C. Brinton, Ionospheric plasma bubble encounters or F region bottomside traversals, J. Geophys. Res., 88, 6243-6252, 1983.

Bittencourt, J. A., Y. Sahai, P. R. Faundes, and H. Takahashi, Simultaneous observations of equatorial F-region plasma depletions and thermospheric winds, J. Atmos. Terr. Phys., 59(9), 1049-1059, 1997.

Buchau, J., E. J. Weber, and J. P. McClure, Radio and optical diagnostics applied to an isolated equatorial scintillation event, in Effect of the Ionosphere Space and Terrestrial Systems, edited by J. M. Goodman, p. 115, U. S. Government Printing Office, Washington, D. C., 1978.

Fagundes, P. R., Y. Sahai, I. S. Batista, M. A. Abdu, J. A. Bittencourt, and $\mathrm{H}$. Takahashi, Vertical and zonal equatorial F-region plasma bubble velocities determined from OI $630 \mathrm{~nm}$ nightglow imaging, Adv. Space Res., 20(6), 1297-1300, 1997.

Fagundes, P. R., Y. Sahai, I. S. Batista, M. A. Abdu, J. A. Bittencourt, and H. Takahashi, Observations of day-to-day variability in precursor signatures to equatorial F-region plasma depletions, Ann. Geophys., 17, 1053-1063, 1999 .

Fejer, B. G., Low latitude electrodynamic plasma drifts, J. Atmos. Terr Phys., 53, 677-693, 1991.

Haerendal, G., Investigation of the equatorial F-region with barium clouds: a review, paper presented at the 6th International Symposium on Equatorial Aeronomy, Sponsored by COSPAR, URSI, IUGG, and IAGA, Aguadilla, Puerto Rico, July 1980 .

Hanson, W. B. and D. K. Bamgboye, The measured motions inside equatorial plasma depletions, J. Geophys. Res., 89, 8997-9008, 1984

Hanson, W. B. and S. Sanatani, Large Ni gradients below the equatorial F peak, J. Geophys. Res., 78, 1167-1173, 1973.

Hanson, W. B., W. R. Coley, R. A. Heelis, and A. L. Urquhart, Fast equatorial bubbles, J. Geophys. Res., 102, 2039-2045, 1997.

Hays, P. B., D. W. Rusch, R. G. Roble, and J. C. G. Walker, The OI (6300 A) airglow), Rev. of Geophys. and Space Phys., 16, 225-232, 1978.

Hysell, D. L., M. C. Kelley, W. E. Swartz, and R. F. Woodman, Seeding and layering of Equatorial spread F by gravity waves, J. Geophys. Res., 95, 17253-17260, 1990

Jahn, J.-M., J. LaBelle, J. H. A. Sobral, T. L. Aggson, and W. B. Hanson, Detection of an equatorial spread-F bubble by ground based photometers and the San Marco 5 satellite, J. Atmos. Sol. Terr. Phys., 59, 1601-1609, 1997.

Kelley, M. C., G. Haerendal, H. Kappler, A. Valenzuela, B. B. Balsley, D. A. Carter, W. L. Ecklund, C. W. Carlson, B. Hausler, and R. Torbert, Evidence for a Rayleigh-Taylor type instability and upwelling of depleted density regions during equatorial spread F, Geophys. Res. Lett., 3, 448450, 1976.

Kelley, M. C., M. F. Larson, C. LaHoz, and J. P. McClure, Gravity wave initiation of equatorial spread F: A case study, J. Geophys. Res., 86, 9087-9100, 1981

Kelley, M. C., J. LaBelle, E. Kudeki, B. G. Fejer, S. Basu, Su. Basu, K D. Baker, C. Hanuise, P. Argo, R. F. Woodman, W. E. Swartz, D. T. Farley, and J. Meriwether, The Condor equatorial spread F campaign Overview and results of the large scale measurements, J. Geophys. Res., 91, 5487-5503, 1986.

Koparkar, P. V. and R. G. Rastogi, VHF radio scintillations at Bombay, J. Atmos. Terr. Phys., 47, 907-910, 1985.

Kudeki, E., B. G. Fejer, D. T. Farley, and H. M. Lerkic, Interferometer studies of equatorial $\mathrm{F}$ region irregularities and drifts, Geophys. Res. Lett., 8, 377-380, 1981

McClure, J. P., W. B. Hanson, and J. F. Hoffman, Plasma depletions and irregularities in the equatorial ionosphere, J. Geophys. Res., 82, 26502656, 1977

Mendillo, M. and J. Baumgardner, Airglow characteristics of equatorial plasma depletions, J. Geophys. Res., 87, 7641-7652, 1982. 
Mendillo, M. and A. Tyler, Geometry of depleted plasma regions in the equatorial ionosphere, J. Geophys. Res., 88(A7), 5778-5782, 1983.

Mendillo, M., J. Baumgardner, M. Colerico, and D. Nottingham, Imaging science contributions to equatorial aeronomy: initial results from the MISETA program, J. Atmos. Sol. Terr. Phys., 59, 1587-1599, 1997a.

Mendillo, M., J. Baumgardner, D. Nottingham, J. Aarons, B. Renisch, J. Scali, and M. Kelley, Investigations of thermospheric-ionospheric dynamics with $6300 \AA$ images from the Arecibo observatory, J. Geophys. Res., 102(A4), 7331-7343, 1997b.

Mukherjee, G. K., L. Carlo, and P. T. Patil, First all sky imaging observations from India, South Pacific STEP Workshop, University of Newcastle, Newcastle, Australia, July 5-9, 1993.

Nottingham, D., M. Mendillo, J. Baumgardner, and M. Kelley, $6300 \AA$ airglow wave structure from Arecibo in January 1993, EOS, 488, 1994.

Raghavarao, R., S. P. Gupta, R. Sekar, R. Narayanan, J. N. Desai, R. Sridharan, V. V. Babu, and V. Sudhakar, In situ measurements of wind, electric fields and electron densities at the onset of equatorial spread F, J. Atmos. Terr. Phys., 49, 485-492, 1987.

Rohrbaugh, R. P., W. B. Hanson, B. A. Tinsley, B. L. Cragin, and J. P. McClure, Images of transequatorial depletions based on field-aligned airglow observations from Haleakala in 1984-1986, J. Geophys. Res., 94, 6763-6770, 1989.

Sahai, Y., J. Aarons, M. Mendillo, J. Baumgardner, J. A. Bittencourt, and H. Takahashi, OI $630 \mathrm{~nm}$ imaging observations of equatorial plasma depletions at $16^{\circ}$ dip latitude, J. Atmos. Terr. Phys., 56, 1461-1475, 1994.

Singh, S., F. S. Johnson, and R. A. Power, Gravity wave initiation of equatorial plasma depletions, J. Geophys. Res., 102(A4), 7399-7410, 1997a

Singh, S., D. K. Bamgboye, J. P. McClure, and F. S. Johnson, Morphology of equatorial plasma depletions, J. Geophys. Res., 102(A9), 20,019-20,029, $1997 \mathrm{~b}$

Sinha, H. S. S., H. Chandra, R. N. Misra, and S. Prakash, Optical imaging of plasma depletions associated with equatorial spread-F, XX General Assembly, IUGG, Vienna, pp. 248, 1991.

Sinha, H. S. S., R. N. Misra, H. Chandra, S. Raizada, N. Dutt, and G. D. Vyas, Multi-Wavelength optical imaging of ionospheric plasma depletions, Ind. J. Rad. and Space Phys., 25, 44-52, 1996.

Sobral, J. H. A., G. L. Borba, M. A. Abdu, I. S. Batista, H. Sawant, C. J. Zamlutti, H. Takahashi, and Y. Nakamura, Post-sunset wintertime 630.0 $\mathrm{nm}$ airglow perturbations associated with gravity waves at low latitudes in the South American sector, J. Atmos. Sol. Terr. Phys., 59, 1611-1623, 1997.

Sridharan, R., H. Chandra, S. R. Das, R. Sekar, H. S. S. Sinha, D. P. Raju, R. Narayanan, S. Raizada, R. N. Misra, R. Raghavarao, P. B. Rao, P. V. S. Ramarao, V. V. Somayajulu, V. V. Babu, and A. D. Danilov, Ionization hole campaign - a co-ordinated rocket and ground based study at the onset of equatorial spread-F: First results, J. Atmos. Sol. Terr. Phys., 59, 2051-2067,1997.

Szuszczewicz, E. P., R. T. Tsunoda, R. Narcisi, and J. C. Holmes, Coincident radar and rocket observations of equatorial spread F, Geophys. Res. Lett., 7, 537-540, 1980 .

Taylor, M. J., J. V. Eccles, J. LaBelle, and J. H. A. Sobral, High resolution OI $(630 \mathrm{~nm})$ image measurements of F-region depletion drifts during the Guará campaign, Geophys. Res. Lett., 24(13), 1699-1702, 1997.

Tinsley, B. A., R. P. Rohrbaugh, and W. B. Hanson, Images of transequatorial F region depletions in 630- and 777-nm emissions compared with satellite measurements, J. Geophys. Res., 102(A2), 2057-2077, 1997.

Tsunoda, R. T., On the spatial relationship of 1-m equatorial spread F irregularities and plasma depletions, J. Geophys. Res., 85, 185-190, 1980.

Tsunoda, R. T., On the generation and growth of equatorial backscatter plume 2. structuring of the west walls of upwelling, J. Geophys. Res., 88, 4869-4874, 1983 .

Tsunoda, R. T. and D. M. Towle, On the spatial relationship of 1-m equatorial spread F irregularities and depletions in total electron content, Geophys. Res. Lett., 6(11), 873-876, 1979

Tsunoda, R. T. and B. R. White, On the generation and growth of equatorial backscatter plumes, 1, Wave structure in the bottom side F layer, $J$ Geophys. Res., 86, 3610-3616, 1981.

Tsunoda, R. T., R. C. Livingston, and C. L. Rino, Evidence of a velocity shear in bulk plasma motion associated with the post-sunset rise of the equatorial F-layer, Geophys. Res. Lett., 8(7), 807-810, 1981.

J. P. McClure, and W. B. Hanson, Equatorial plasma depletions: vertically elongated wedges from the bottomside F layer, J. Geophys. Res., 87, 9171-9180, 1982

Weber, E. J., J. Buchau, R. H. Eather, and S. B. Mende, North-south aligned equatorial airglow depletions, J. Geophys. Res., 83, 712-716, 1978.

Weber, E. J., J. Buchau, and J. G. Moore, Airborne studies of equatorial F layer Ionospheric irregularities, J. Geophys. Res., 85(A9), 4631-4641, 1980.

Weil, G. and J. Joseph, Premiers measures du triplet $3^{5} \mathrm{~S}^{0}-3^{5} \mathrm{P}$ de OI, á 7772 7774 , et $7775 \AA$ emis par le nocturne des régions tropicales, C. R. Acd. Sci., Ser. B, 271, 1013-1016, 1970.

Woodman, R. F. and C. LaHoz, Radar observations of F region equatorial irregularities, J. Geophys. Res., 81, 5447-5466, 1976.

Zalesak, S. T., S. L. Ossakow, and P. K. Chaturvedi, Nonlinear Equatorial spread F: The effects of neutral winds and background Pedersen conductivity, J. Geophys. Res., 87, 151-166, 1982.

H. S. S. Sinha (e-mail: hsinha@prl.ernet.in) and S. Raizada 